\title{
What should be the role of the media in nutrition communication?
}

\author{
Laura Fernández-Celemín* and Anna Jung \\ European Food Information Council (EUFIC), 19 Rue Guimard, B-1040 Brussels, Belgium
}

\begin{abstract}
The increasing availability of nutrition and health information has not always increased the knowledge of the general population, but presents them with the need to know and understand in order for choices to be made. While communicating science to the lay public, several challenges are encountered, ranging from the heterogeneity of the audience, the consumers, who demand certainty and a straightforward message, through the different aims and agendas of all the communicators, to the inherent complexity of the scientific message. Nowadays, the media is one major source of scientific information to the general public. The present article examines what the role of the media and scientists should be in bringing scientific communication to the public and how this communication could be improved.
\end{abstract}

Science communication: Nutrition communication: Media

The demand for information on nutrition has grown exponentially in the last few years. People are interested in food more than on a basic level and are also more and more concerned about their health. This is reflected in the huge media coverage in magazines, newspapers, radio, television programmes and the Internet.

The increased availability of scientific information has not always increased people's knowledge, but presents them with the obligation to know and understand in order to make choices.

This creates a greater need for 'trust' in the nutrition information. Trust only comes from presenting balanced information from credible sources, and from communicating these in ways which the general population will understand.

There are several challenges when communicating balanced scientific information to consumers (Harrabin et al. 2003):

- Consumers are not scientists and they already have preformed views.

- They want certainty; they want to know whether things are healthy or unhealthy.

- They find it difficult to change food behaviour.

- Not all consumers are the same. So one size fits all does not work in nutrition communication.

In addition:

- There is a significant difference between the media, trying to put things as simply as possible, and scientists trying to avoid simplification and absolutes.

- Uncertainty is unavoidable in nutrition research and 'perfect' research does not exist.

- There is a constant need to update the information. The scientific process is a process that frequently moves in many different directions, generating questions, discussions and debates along the way.
- The term 'expert' has been abused, resulting in confusion of the consumer and undermining the credibility of all experts.

How emerging nutritional science is communicated - by scientists, the journals, the media and the many interest groups that influence the process - can have powerful effects on the public's understanding, on its behaviour and, ultimately, on its well-being. That is why it is so important that foodrelated science is effectively communicated in ways that serve both public understanding and the objectives of communicators (National Association of Science Writers, 1998).

The media, health professionals and educators are the gatekeepers of today's food and health information. They determine, for the most part, what consumers hear, read and believe about food and health. Along with that comes the responsibility to provide the facts, put them in perspective, and help people determine how the findings may affect their behaviour and lives (Fineberg \& Rowe, 1998).

Among them, the media is probably nowadays the most important single information source on health and nutrition for the public. Thus, helping journalists to produce factual, intelligible, timely information on those topics is of critical importance.

There is often the assumption in the scientific community that the media is not trustworthy, whereas scientists are. This is probably no longer true. Nowadays, as people get more used to greater amounts of information, they have become more skilled at accessing it (mostly via the Internet) and applying their own filters. They base their everyday decisions on what they hear or see in the mass media. Therefore, the scientific community can no longer afford to dismiss its importance and value. The mass media provides the forum in which the relationship between science and the public is constructed and pursued, and it is in this forum that the public make moral judgements about science. 
How should the communicators, particularly the media, manoeuvre through the maze of emerging scientific findings about food and health to deliver accurate, relevant information to the public? Firstly, by reserving judgement about a scientific study until they have sought out other studies and experts to help assess the findings of the study and its importance - or unimportance. In other words, by putting all research into context. Secondly, by taking a moderate approach to communicating new information, realizing that what may seem to be a revolutionary, life-altering study today may turn out to be just the opposite tomorrow. Any short-term gain in publicity will be more than offset by long-term distrust. Journalists reporting on scientific issues, such as nutrition and health, have a further unique responsibility to the reader. Unlike other journalists, such as sports writers, whose readers already know the rules of the game and who the players are, science journalists must often introduce readers to a new 'game' with every article. They must first understand the science and then translate it accurately into a form that is both interesting and intelligible to the layperson. Even though they tend to be among the most conscientious of journalists, they are still journalists first and not scientists. Good science journalists do their best to report accurately, but always keeping in mind what they think will interest the public (Social Issues Research Centre, 2001).

Moreover, the role of the media is not, in the first instance, to educate. The role of the media is to sell more papers, attract more viewers, etc. - basically, they are commercial enterprises. This means that the role of the media is primarily to inform and entertain; if that also results in education then the better, but it is not necessary. In practice, this means that the press is naturally attracted to scares, scandals, conflicts and all the other things which bring a frisson of excitement to their public. This does not make them evil, but it does need to be understood if they are to be part of the nutritional education mix.

In a sense, the press is both a window and a mirror. It shows its readers/viewers other lives and possibilities, but it also reflects back to them its own views and prejudices. People tend to read newspapers, for example, which share their own political views and validate their views on life. They do not read newspapers to be actively challenged. This means that the press, far from driving the nutritional debate, is more likely to contribute to the inertia of it, which is a greater force against change than active hostility.

In summary, the media has to be seen as an important partner, with its own views and agenda, rather than a delivery mechanism for scientific messages.

In practice, this means that the scientific community needs to respond to the media's desire for simplicity and not simply reject it as childish. Scientists need to take the time to explain as many times as is needed, giving perspective or more information on the significance of findings and open itself to media scrutiny and questioning. Scientists should understand that most reporters want accurate stories as much as they do and cooperating with the media makes it far more likely that the resulting stories will be precise and correct.

The scientific community also has an ethical and professional obligation to the public. Science enriches human life and can improve the lives of many people. The public is the ultimate audience for scientific information and supports most research through taxes. Thus, the public has the right to receive accurate information on the basis of which individuals can make informed life-style decisions. Besides, media coverage of scientific findings is also beneficial for the scientific community. It increases general interest in science, which will ultimately result in scientific research funding and more fellow researchers. Scientists should consider that they are not communicating to the media, but using it to communicate with a variety of audiences (Nelkin, 1995).

Another important point is that scientific communication should focus more on the consumer but at the same time be realistic, with a common understanding of the notion of risk, as the public reacts to the strongest expression of risk and in general the media tends to be risk exaggerated. This means that common guidelines are needed for all communicators.

These guidelines could be simple hypothetical questions to be used by journalists and scientists as a rule of thumb to help judge where the public interest lies. They should be generally adopted and:

- They should cover the most appropriate way to report risk.

- They should provide standards of accuracy and balance.

- They should help put information into context and measure its relevance.

- They should take into account funding and other 'interests' that might exist.

- They should cover the practical needs of all parties (e.g. deadlines for journalists).

In the case of journalists, guidelines should be elaborated by journalists to help them distinguish clearly between fact and conjecture. The guidelines could be questions on the credibility of the sources, appropriateness of research methods used, the significance of findings, as well as communicating the risk or anticipating the impact.

The same applies for scientists, who have an equal obligation to ensure that they present their findings to the public in an accurate and responsible way and should also follow guidelines developed by scientists in order to help them communicate accurately to journalists. On their side, they should be informed on how to deal with the media, be accurate and tell the truth, be careful and clear when communicating risk and benefits and complain if things are misquoted.

While guidelines cannot ensure error-free communication, following these precepts should increase accuracy and reduce misrepresentation and distortion and contribute to the aim of promoting general understanding. This process of open and non-confrontational exchange should lead not only to more balanced and accurate reporting of health and science issues, but also much improved working relationships between scientists and the media, the final goal being to achieve greater understanding of science's public education responsibilities.

\section{References}

Fineberg HV \& Rowe SB (1998) Improving public understanding: guidelines for communicating emerging science on nutrition, food safety, and health. J Natl Cancer Inst 90, 194-199. 
Harrabin R, Coote A \& Alle J (2003) Health in the News: Risk, Reporting and Media Influence. London: King's Fund Publications.

National Association of Science Writers (1998) Communicating Science News: A Guide for Public Information Officers, Scientists and Physicians. http://nasw.org/csn/
Nelkin D (1995) Selling Science: How the Press Covers Science and Technology. New York: WH Freeman \& Company.

Social Issues Research Centre (2001) In Partnership with the Royal Society and the Royal Institution of Great Britain. Guidelines on Science and Health Communication. http://www.sirc.org/publik/ $\underline{\text { revised_guidelines.shtml }}$ 